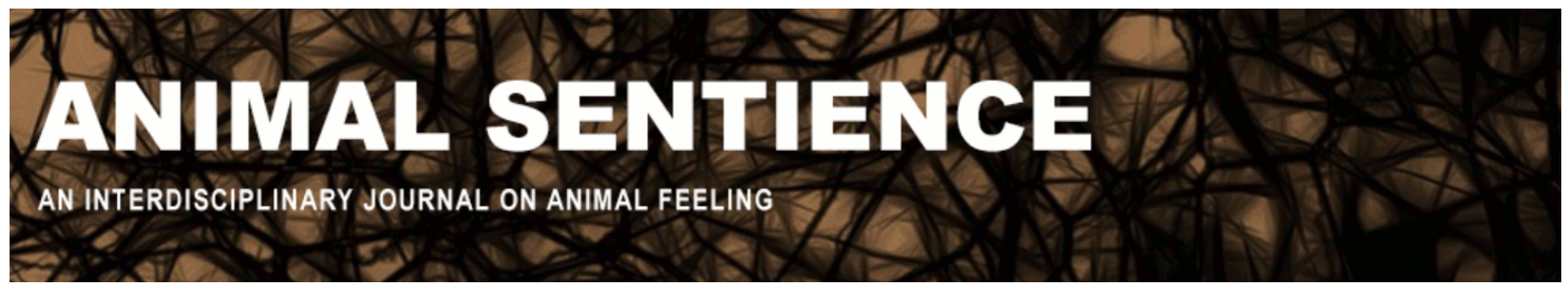

Carder, Gemma (2017) A preliminary investigation into the welfare of lobsters in the UK. Animal Sentience 16(19)

DOI: $10.51291 / 2377-7478.1262$

Date of submission: 2017-11-21

Date of acceptance: 2017-12-01

(c) (†)

This article has appeared in the journal Animal

Sentience, a peer-reviewed journal on animal

cognition and feeling. It has been made open access,

free for all, by WellBeing International and deposited

in the WBI Studies Repository. For more information,

please contact

wbisr-info@wellbeingintl.org.

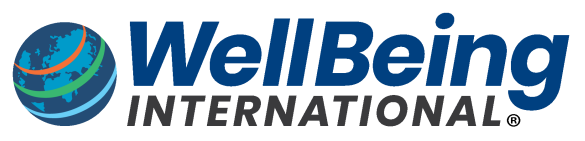

SOLUTIONS FOR PEOPLE, ANIMALS AND ENVIRONMENT 
[This commentary raises the question of decapod welfare; commentary on this commentary can be submitted as commentary on Birch and the author, Gemma Carder, will respond - ed.]

\title{
A preliminary investigation into the welfare of lobsters in the UK
}

Commentary on Birch on Precautionary Principle

\author{
Gemma Carder \\ Crustacean Compassion, London, United Kingdom
}

\begin{abstract}
The welfare of invertebrates is overlooked and their needs are not understood. It is assumed that they do not experience pain and suffering. Studies on decapod crustaceans challenge this assumption. Research has focused on distinguishing between nociception (the ability to detect a harmful stimulus and to react to it reflexively) and pain (an aversive feeling or emotional experience). Findings indicate that decapod crustaceans can experience pain, which supports a case for protecting their welfare. I have investigated the current husbandry conditions of a globally consumed decapod crustacean, the lobster, as housed in tanks inside food outlets in the UK. Housing conditions of 325 lobsters were scored on four factors: restraints, stocking density, lighting and shelter. The data indicate that the basic requirements for lobsters are not being met, thereby compromising their welfare. I recommend research on the welfare of lobsters and other decapod crustaceans, not only when housed in tanks, but also during capture, handling and transport. Such information can be used to inform legislative change.
\end{abstract}

Keywords: decapod crustaceans, animal sentience, emotions, invertebrates, animal welfare, precautionary principle

Gemma Carder is a researcher for World Animal Protection and a scientific advisor for Crustacean Compassion. Gemma's research is on domestic and wild animal behaviour and welfare. Her recent research has centred on identifying behavioural and physiological measures of emotional states in dairy cows. She has an interest in applying research findings to aid animal welfare campaigns. www.researchgate.net/profile/Gemma_Carder

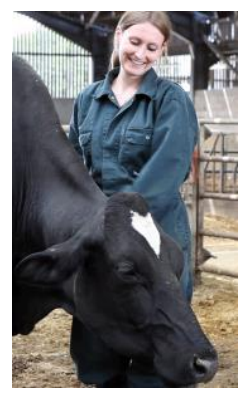

\section{Introduction}

Most research into animal welfare to date has focused on vertebrates. Invertebrate welfare is comparatively neglected (Sherwin, 2001; Mather and Anderson, 2007; Horvath et al., 2013). They are less valued and understood than vertebrates, and many people are afraid of them (Nash, 2004). There is also an assumption that invertebrates have less capacity to experience pain and suffering and that therefore consideration of their welfare is not warranted (Sherwin, 2001; Horvath et al., 2013). As invertebrates, decapod crustaceans are not included in the 
definition of 'animals' under any of the UK's Animal Welfare Acts, meaning that retailers, processors and consumers are under no obligation to consider their welfare during storage, handling or slaughter. Since research has shown that a lobster boiled alive can take up to three minutes to die (Roth \& Grimsb $\varnothing$, 2013), these assumptions deserve much closer inspection.

1.1. Sentience. Although studies exploring pain in invertebrates have increased in recent years, compared with vertebrates the research is still limited (Proctor et al., 2013; Sherwin, 2001; Hovarth et al., 2013). Regarding decapod crustaceans, Professor Robert Elwood at Queen's University Belfast, has performed numerous studies exploring pain in a small number of species. His research has focused primarily on distinguishing between nociception, which refers to the ability of an individual to detect a harmful stimulus and to react to it in a reflexive manner, and an aversive feeling or emotional experience characterised as pain (Barr et al., 2007; Sneddon, 2004). Nociception provides immediate protection from tissue damage, whereas pain enables longer term protection (Elwood, 2012). Criteria have been identified which may help distinguish between pain and nociception (Elwood, 2012). In relation to decapods, criteria include avoidance learning, physiological responses, protective motor reactions, motivational trade-offs, opioid receptors, and evidence of reduced pain experience when treated with anaesthetics or analgesics (Elwood et al., 2009; Elwood, 2012).

Elwood reports that findings to date indicate that all criteria for pain are met by decapods, suggesting that they do experience pain (Elwood, 2012; Elwood and Appel, 2009). For example, Patterson et al. (2007) found that de-clawing live edible crabs resulted in a physiological stress response; this response was evident both in the short term (1-10 minutes) and the longer term ( 24 hours). Furthermore, when vertebrates experience pain, they often lick, rub or groom the affected area (Weary et al., 2006). Some species of decapods have been found to exhibit similar behaviour (Barr et al., 2008): Glass prawns show a significant increase in grooming and rubbing when acetic acid is rubbed onto one antenna (Barr et al., 2008). The grooming and rubbing was directed towards the affected antenna (Barr et al., 2008). An experiment with hermit crabs found that when exposed to electric shock, more crabs evacuated their shells than in the control group (Appel \& Elwood, 2009). The crabs retained a memory of the shock for up to 24 hours and were observed exploring the shell afterwards to try and locate the source of the pain (Elwood \& Appel, 2009). Fewer crabs evacuated their shells when they had a preferred shell species; more evacuated when their shell was lesspreferred: a motivational trade-off (Elwood \& Appel, 2009). When a response pattern like this is observed in vertebrates, it is interpreted as awareness of a painful stimulus (Gherardi, 2009).

Magee and Elwood (2013) write: "These data, and those of other recent experiments, are consistent with key criteria for pain experience and are broadly similar to those from vertebrate studies." Elwood (2012) also states that the evidence is just as strong as it is for fish, but pain has broader acceptance in fish than in decapods, and that this represents a taxonomic bias. Elwood suggests that both taxa should be treated as though they are able to experience the negative affective state of pain. The European Food Safety Authority (EFSA, 2005) reviewed the evidence of the ability of decapod crustaceans to experience pain and accordingly classed all decapod crustaceans as 'Category One' animals, the category for which the scientific evidence "clearly indicates that animals in those groups are able to experience pain and distress."

1.2. The precautionary principle. In light of the recent evidence that decapod crustaceans are probably sentient, some do agree that we should err on the side of caution in how we treat 
them (Mason, 2011; Sherwin, 2001; Horvath et al., 2013) and that there is a substantial case for legally protecting them (Broom, 2007). Birch (2017) asks how much evidence it should take to convince us that an animal is sentient, and when the precautionary principle should be invoked in designing legislation. As mental states are private, it is impossible to ascertain conclusively the subjective experiences of another (Dawkins, 2001; Proctor, 2012; Sherwin, 2001). Considering this, should the precautionary principle where the species or taxa in question is given the benefit of the doubt be applied to decapod crustaceans? Although only a small number of decapod crustaceans have been investigated for their ability to experience pain, Birch (2017) argues that the precautionary principle should be applied to the entire order. This is because it is practically impossible to test for sentience in all 15,000 species of decapod crustaceans (Birch, 2017). If we have evidence of sentience in one species, argues Birch (2017), then the welfare of all species (within the taxon) should be considered.

1.3. Lobster habitat preference and behaviour. Considering what is known about the likely ability of decapods to suffer, there are currently a number of practices that may compromise their welfare (Elwood et al., 2009). Furthermore, lobsters have certain preferences which may be overlooked in the captive environment. In natural environments, adult lobsters are usually found on rocky sea beds in depths of 100 metres of more (Beard \& McGregor, 2004). They prefer areas where there are crevices to provide shelter (Beard \& McGregor, 2004). It has been suggested that the ability to find shelter is a critical factor for wild lobsters (Aspaas et al., 2016). Lobsters are primarily nocturnal animals and emerge from cover as darkness falls to forage for food, before returning to shelter when the light level starts to increase (Beard \& McGregor, 2004). Lobsters do not like strong light. Captive lobsters should have dim lighting over their tanks during the day and the avoidance of sudden increases in light levels is also advisable (Beard \& McGregor, 2004). Lobster preference for dark areas was highlighted in a study where European lobsters were presented with a maze during periods when lights were turned on and off. Five minutes after the lights were turned off, the lobsters left their shelters and started to roam the maze (Mehrtens et al., 2005). During the light period, the lobsters remained in their shelters and left them only occasionally (Mehrtens et al., 2005). In relation to the social behaviour of lobsters, both American and European lobsters are solitary (Beard \& McGregor, 2004; Karavanich \& Atema, 1998). Aggressive competition for shelter and territory is a key part of their behavioural repertoire (Beard \& McGregor, 2004). Assuming that the precautionary principle should be applied to decapod crustaceans, and considering their habitat and behavioural preferences, I aimed to investigate the current husbandry conditions of a globally consumed decapod crustacean, the lobster.

\section{Methods}

2.1. Subjects and housing. Nine retailers (food outlets) housing American (Homarus americanus) and European (Homarus gammarus) lobsters were visited by four researchers between May 30 and July 15, 2017. Eight of these retailers were in London, UK, and one was in Brighton, UK. The facilities were selected based on convenience, and where lobsters were on display to the public. The lobsters were housed in 26 tanks. The number of tanks at each facility ranged from 1 to 6 . The researchers overtly took images of the tanks at each of the locations at each site for examination later. The number of lobsters in each tank was counted, and the approximate dimensions of the tanks (to the water level) were also recorded ( $L \times W \times$ $\mathrm{H} \mathrm{cm}$ ). 
2.2. Husbandry welfare scoring. One researcher reviewed the images of the 26 tanks, and scored the lobsters' living conditions using the husbandry welfare score (Table 1). The lobster welfare score was developed based on some basic welfare needs of lobsters. This tool does not cover all aspects of lobster welfare, but includes the factors that could be scored from images. The factors included restraints, stocking density, lighting, and provision of shelters (refer to Table 1 for descriptions). A score between 0 and 4 was given to each of the tanks at each facility.

\begin{tabular}{|l|l|l|l|l|l|}
\hline Welfare score & $\mathbf{0}$ & $\mathbf{1}$ & $\mathbf{2}$ & $\mathbf{3}$ & $\mathbf{4}$ \\
\hline Restraints & $\begin{array}{l}\text { 100\% of lobsters } \\
\text { have both claws } \\
\text { banded. }\end{array}$ & $\begin{array}{l}\text { Intermediate of 0 } \\
\text { and 2. }\end{array}$ & $\begin{array}{l}\text { 50\% of lobsters } \\
\text { have both claws } \\
\text { banded. }\end{array}$ & $\begin{array}{l}\text { Intermediate of 2 } \\
\text { and 4. }\end{array}$ & $\begin{array}{l}\text { None of the lobsters } \\
\text { have either of their } \\
\text { claws banded. }\end{array}$ \\
\hline $\begin{array}{l}\text { Stocking } \\
\text { density }\end{array}$ & $\begin{array}{l}\text { All lobsters are } \\
\text { stacked on top of } \\
\text { each other in 2 or } \\
\text { more layers. }\end{array}$ & $\begin{array}{l}\text { Intermediate of 0 } \\
\text { and 2. }\end{array}$ & $\begin{array}{l}\text { All lobsters are in } \\
\text { close proximity } \\
\text { (next to each } \\
\text { other along the } \\
\text { bottom of the } \\
\text { tank in a single } \\
\text { layer. }\end{array}$ & $\begin{array}{l}\text { Intermediate of 2 } \\
\text { and 4. }\end{array}$ & $\begin{array}{l}\text { Each lobster has a } \\
\text { small amount of } \\
\text { space around them } \\
\text { where they do not } \\
\text { come into } \\
\text { immediate physical } \\
\text { contact with others. }\end{array}$ \\
\hline Lighting & $\begin{array}{l}\text { The tank has very } \\
\text { bright artificial } \\
\text { lighting. }\end{array}$ & $\begin{array}{l}\text { Intermediate of 0 } \\
\text { and 2. }\end{array}$ & $\begin{array}{l}\text { Artificial lighting is } \\
\text { present but is not } \\
\text { considered bright } \\
\text { or dim. }\end{array}$ & $\begin{array}{l}\text { Intermediate of 2 } \\
\text { and 4. }\end{array}$ & $\begin{array}{l}\text { The tank has very } \\
\text { dim lighting or is } \\
\text { dark. }\end{array}$ \\
\hline Shelters & $\begin{array}{l}\text { There are no } \\
\text { shelters. }\end{array}$ & $\begin{array}{l}\text { Intermediate of 0 } \\
\text { and 2. }\end{array}$ & $\begin{array}{l}\text { 50\% of individuals } \\
\text { have access to an } \\
\text { individual shelter. } \\
\text { The shelters are } \\
\text { big enough for } \\
\text { their whole body. }\end{array}$ & $\begin{array}{l}\text { Intermediate of 2 } \\
\text { and 4. }\end{array}$ & $\begin{array}{l}\text { Each lobster has } \\
\text { their own shelter } \\
\text { that is big enough } \\
\text { for their whole body. }\end{array}$ \\
\hline
\end{tabular}

Table 1. Lobster husbandry welfare score.

\begin{tabular}{|c|c|c|c|c|c|c|}
\hline Facility number & Tank number & $\begin{array}{l}\text { Count of } \\
\text { lobsters }\end{array}$ & Restraints & Stocking density & Lighting & Shelter \\
\hline 1 & 1 & 11 & 0 & 4 & 2 & 0 \\
\hline 2 & 1 & 14 & 0 & 1 & 2 & 0 \\
\hline 2 & 2 & 13 & 0 & 1 & 2 & 0 \\
\hline 2 & 3 & 12 & $*$ & 1 & 2 & 0 \\
\hline 2 & 4 & 4 & 0 & 3 & 2 & 0 \\
\hline 3 & 1 & 20 & 0 & 3 & 1 & 0 \\
\hline 3 & 2 & 20 & 0 & 2 & 1 & 0 \\
\hline 3 & 3 & 4 & 0 & 4 & 0 & 0 \\
\hline 4 & 1 & 7 & 0 & 2 & 1 & 0 \\
\hline 4 & 2 & 22 & 0 & 1 & 1 & 0 \\
\hline 4 & 3 & 45 & 0 & 0 & 2 & 0 \\
\hline 4 & 4 & 14 & 0 & 3 & 2 & 0 \\
\hline 5 & 1 & $*$ & $*$ & 4 & 1 & 0 \\
\hline 5 & 2 & * & * & 4 & 1 & 0 \\
\hline 5 & 3 & $*$ & $*$ & 4 & 2 & 0 \\
\hline 5 & 4 & $*$ & $*$ & 4 & 1 & 0 \\
\hline 6 & 1 & 19 & 0 & 3 & 3 & 0 \\
\hline 6 & 2 & 23 & 0 & 1 & 1 & 0 \\
\hline 6 & 3 & 22 & 0 & 3 & 3 & 0 \\
\hline 6 & 4 & 20 & 0 & 0 & 1 & 0 \\
\hline 6 & 5 & $*$ & 0 & 2 & 1 & 0 \\
\hline 6 & 6 & $*$ & 0 & 1 & 1 & 0 \\
\hline 7 & 1 & 20 & 0 & 0 & 2 & 0 \\
\hline 7 & 2 & 25 & 0 & 0 & 2 & 0 \\
\hline 8 & 1 & $*$ & $*$ & 3 & 2 & 0 \\
\hline 9 & 1 & 10 & 0 & 1 & 3 & 0 \\
\hline
\end{tabular}

Table 2. Welfare score for each of the four factors (restraints, stocking density, lighting, and shelter) for each tank at each facility. *unavailable data. 


\section{Results}

3.1. Number of lobsters and tank size. In total, 325 lobsters could be scored on all criteria at 7 of the 9 facilities, and in 19 of the 26 tanks. At two of the facilities, the number of lobsters could not be estimated, as there were too many and/or a restricted view. The number of lobsters in each tank ranged from 4 to 45 . The dimensions of 21 of the tanks were estimated (to the water level), but the dimensions of five of the tanks could not be accurately estimated. From the estimated measurements, the $\mathrm{cm}^{3}$ of each tank were calculated. The tanks ranged in size from 108,000 to $810,000 \mathrm{~cm}^{3}$.

3.2. Welfare scores. Regarding the welfare issue of restraints, 20 of the 26 tanks were scored. All 20 tanks scored 0 , meaning that $100 \%$ of lobsters had both claws banded with elastic bands. For stocking density, all 26 tanks were scored, and the scores varied considerably between the tanks. Score 1 was the most common score given $(n=7)$, followed by $3(n=6)$ and $4(n=6)$. All 26 tanks were scored for lighting. Two was the most common score $(n=11)$, followed by $1(n=10)$. For shelter, all 26 tanks were scored. All tanks scored 0, therefore, 100\% of lobsters did not have access to a shelter within their tanks.

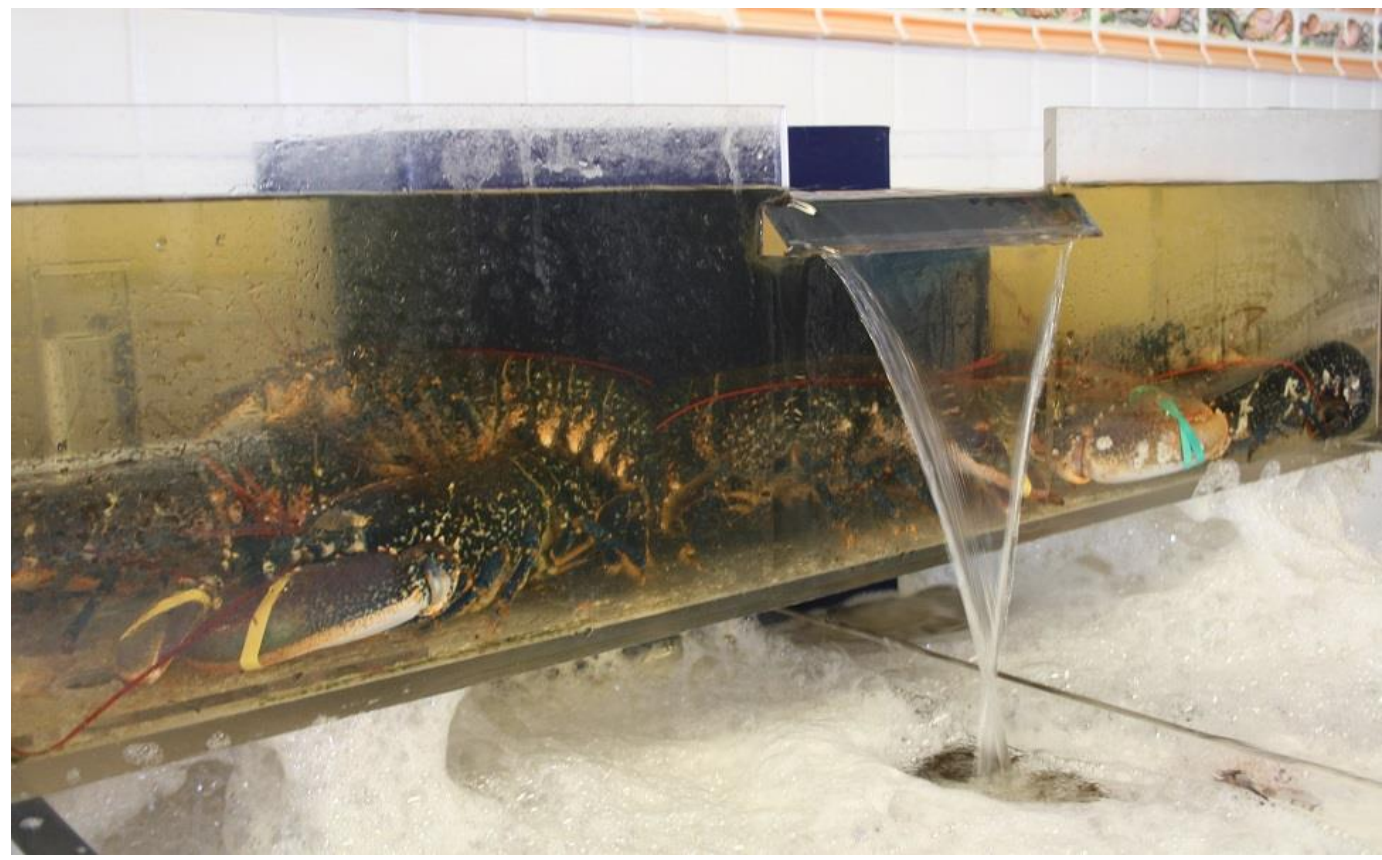

Figure 1. Lobsters in a tank at a UK supermarket.

\section{Discussion}

4.1. Welfare scores. Our preliminary study suggests that a large number of lobsters are currently experiencing compromised welfare. Our study investigated four primary factors: restraints, stocking density, lighting, and shelter. For restraints, $100 \%$ of lobsters had their claws banded. Lobsters are often banded to prevent them from causing injury to one another and to the people who handle them. It could accordingly be argued that there are potential welfare benefits. However, having both claws banded is highly restrictive, since lobsters use their claws for locomotion, feeding and defence (Beard \& McGregor, 2004). Although from this research it cannot be determined what effect being banded may have on the psychological well-being of lobsters, it does prohibit freedom to express normal behaviour. 
For the factor of stocking density, the most common score was 1, followed by 3 and 4 . Score 1 is a low score, with the lobsters being crowded and in close proximity to each other. As lobsters are solitary (Beard \& McGregor, 2004; Karavanich \& Atema, 1998), it is highly likely that being in close proximity to a number of individuals causes stress; however, research in this context would be needed to support this assumption. The scores did vary between the tanks, and even between tanks within the same food outlet. There hence appeared to be inconsistent standards in relation to the level of crowding permitted. Twelve of the tanks were given high scores ( 3 and 4), although this may represent low levels of 'stock' on the day visited. To gain a better understanding, the facilities would need to be visited several times on different days to assess whether the stocking density score stays consistent or changes at different times and on different days.

For lighting, 2 was the most common score given, followed by 1 . Score 2 represents the presence of artificial lighting which appears more 'natural.' Score 1 is an intermediate between bright artificial lighting and a more 'natural' artificial light. It is likely that the food outlets use artificial lighting so that customers can clearly see the lobsters they are purchasing. Research has shown that lobsters have a preference for dark areas (Beard \& McGregor, 2004; Mehrtens et al., 2005); being exposed to bright artificial lights for long periods of time may hence cause stress and compromised welfare. All tanks scored 0 in relation to the shelter factor. It is likely that the absence of shelters compromises welfare; in breeding facilities, shelters are considered to be enrichment for lobsters, contributing to higher welfare conditions (Carere et al., 2012).

4.2. Limitations and future research. Our preliminary investigation was limited to a small number of food outlets in the UK during a short period of time. Our findings, therefore, provide only a glimpse into the husbandry conditions of lobsters being used in the food industry in the UK. There were limitations to the data collection method. Images were taken with more than one device; the images were therefore not taken in a standardised way, which could have affected the scores given for lighting. Future research could score lighting directly at the facilities, rather than from images.

Four factors were focused on; future research needs to explore other factors which may compromise the welfare of lobsters housed in tanks. This may include water quality, for example, ammonia and oxygen levels; lobsters are also sensitive to disturbances, and may become stressed when subjected to loud or sudden noise, caused by customers and staff (Beard \& McGregor, 2004). It would be desirable to investigate the impact of loud noise and disturbances on the behaviour of lobsters. It would also be helpful to measure how long lobsters are housed in tanks in food outlets, perhaps by conducting interviews with staff members. This would allow an assessment on the duration of potential suffering. Further research could also assess the impact of potential improvements in lobster housing, such as the provision of shelters, on their behaviour and welfare; the common practice of live delivery to customers via online shopping needs to be investigated too. Our study focused on the welfare of lobsters housed in tanks in food outlets in the UK. Research also needs to focus on additional areas and could include catching and handling methods, transportation, and slaughter methods. Findings from such research can increase understanding of how current practices affect the welfare of lobsters and other decapod crustaceans, and could help in the development of improved standards of care and slaughter. 
4.3. Recommendations. Birch has suggested that in applying the precautionary principle we should give the species' entire order the benefit of the doubt in developing and implementing animal protection legislation. Currently, lobsters and other decapods receive little legal protection on a global level (Elwood, 2012; Horvath et al., 2013). Exceptions to this are New Zealand, Norway, Switzerland and some Australian states, where they are included in animal welfare legislation. In Swiss legislation, decapod crustaceans are protected by the secondary regulations of the Federal Food Safety and Veterinary Office through Animal Welfare Ordinance 2008, which outlines regulations for animal husbandry, transport and slaughter. Decapod crustaceans are granted protection under general husbandry guidelines, including: "the right to be fed, housed alone in an appropriate manner, cared for in a way which prevents injury and disease, and individuals are allowed the opportunity to perform species specific behaviour." The Norwegian Animal Welfare Act 2010 states "Animals have an intrinsic value which is irrespective of the usable value they may have for man. Animals shall be treated well and be protected from danger of unnecessary stress and strains." Decapod crustaceans are included in this act. In contrast, in the UK, animal welfare laws do not apply to decapod crustaceans, and so there are no regulations in place to protect them.

I would recommend that the legislation regarding the welfare of decapod crustaceans be reviewed taking full account of the latest scientific evidence. When the Animal Welfare Bill was introduced in 2005, decapods were narrowly excluded as being "right on the cusp" in terms of evidence supporting their sentience. However, legislative space was made in all UK regions to allow for the possibility of further evidence supporting their inclusion (and that of other invertebrates). For example, Section 1 (3), (4) of the Animal Welfare Act 2006 of England and Wales states that the appropriate national authority may "extend the definition of "animal" to include invertebrates of any description.... if the appropriate national authority is satisfied, on the basis of scientific evidence, that those animals are capable of experiencing pain or suffering." Similar clauses are included in Scotland's Animal Health and Welfare Act 2006, and Northern Ireland's Welfare of Animals Act 2011.

As this commentary has indicated, the latest research points strongly to the conclusion that decapods are capable of pain and suffering. Despite this, a Freedom of Information Request made in January 2017 by campaign group Crustacean Compassion revealed that the government has not conducted or commissioned any scientific assessment of the sentience of decapod crustaceans since the Animal Welfare Bill was debated in 2005 (Maisie Tomlinson, pers. comm., 2017).

\section{Conclusion}

Our study provides an important initial insight into a neglected area of investigation, and serves as a starting point for future research. Assuming that decapod crustaceans should be given the benefit of the doubt in terms of their ability to suffer, findings from this study already demonstrate that lobsters being used in the food industry in the UK are experiencing compromised welfare. Lobsters are being restrained, housed in overcrowded conditions, and their biological preferences for dark places and shelter are not being met. Unlike in some countries, in the UK, lobsters and other decapod crustaceans are not protected by legislation during capture, handling, housing or slaughter. We suggest that future research explore the welfare of lobsters and other decapods further, and that the resultant findings be used to improve standards of care and influence changes in legislation. 
Acknowledgements: I would like to thank The Sheila McKechnie Foundation for providing funding to Crustacean Compassion to carry out the work of the organisation. I would like to give special thanks to Maisie Tomlinson, Juliette Booker, Joanna Randall and Ann Broadhurst for their support in data collection and for providing comments on the paper. I would also like to thank Helen Lambert and Laura McAnea for providing constructive feedback on the paper.

\section{References}

Appel, M., \& Elwood, R. W. (2009). Motivational trade-offs and potential pain experience in hermit crabs. Applied Animal Behaviour Science, 119(1-2), 120-124. http://doi.org/10.1016/j.applanim.2009.03.013

Aspaas, S., Grefsrud, E. S., Fern, A., Jensen, K. H., Trengereid, H., \& Agnalt, A. L. (2016). An enriched environment promotes shelter-seeking behaviour and survival of hatcheryproduced juvenile European lobster (Homarus gammarus). PLOS ONE, 11(8), 1-16. http://doi.org/10.1371/journal.pone.0159807

Barr, S., Laming, P. R., Dick, J. T. A., \& Elwood, R. W. (2008). Nociception or pain in a decapod crustacean? Animal Behaviour, 75(3), 745-751. http://doi.org/10.1016/j.anbehav.2007.07.004

Beard, T. W., \& McGregor, D. (2004). Storage and care of live lobsters. Laboratory Leaflet (Revised), 66(66), 1-27. http://doi.org/10.1016/j.jembe.2005.07.015

Birch, J. (2017). Animal sentience and the precautionary principle. Animal Sentience, 16(1).

Broom, D. M. (2007). Cognitive ability and sentience: which aquatic animals should be protected? Diseases of Aquatic Organisms, 75(2), 99-108. http://doi.org/10.3354/dao075099

Carere, C., Della Gala, M., Saraga, E., Grignani, G., Delle Fratte, R., Carlini, A., Angeletti, D., Alleva, E., Mather, J.A., \& Nascetti, G. (2012). The shelter matters: Effect of rearing conditions on the behavioural profiles of juvenile lobsters (Homarus gammarus) bred for restocking purposes. In Carere et al. (Eds.), Abstract book XXV Meeting of The Italian Society of Ethology (SIE), Department of Ecological and Biological Sciences, University of Tuscia, Viterbo, Italy, p. 80.

Dawkins, M. I. S. (2001). Who needs consciousness? Animal Welfare, 10, S19-29.

EFSA. (2005). Scientific opinion on aspects of the biology and welfare of animals used for experimental and other scientific purposes.

Elwood, R. (2012). Evidence for pain in decapod crustaceans. Animal Welfare, 21(1), 23-27. http://doi.org/10.7120/096272812X13353700593365

Elwood, R. W., \& Appel, M. (2009). Pain experience in hermit crabs? Animal Behaviour, 77(5), 1243-1246. http://doi.org/10.1016/j.anbehav.2009.01.028

Elwood, R. W., Barr, S., \& Patterson, L. (2009). Pain and stress in crustaceans? Applied Animal Behaviour Science, 118(3-4), 128-136. http://doi.org/10.1016/j.applanim.2009.02.018

Gherardi, F. (2009). Behavioural indicators of pain in crustacean decapods. Annali dell'Istituto Superiore Di Sanità, 45(4), 432-438. Retrieved from http://www.ncbi.nlm.nih.gov/pubmed/20061665

Horvath, K., Angeletti, D., Nascetti, G., \& Carere, C. (2013). Invertebrate welfare: an overlooked issue. Annali dell'Istituto superiore di sanità, 49 (1), 9-17.

Karavanich, C., \& Atema, J. (1998). Individual recognition and memory in lobster dominance. Animal Behaviour, 56(6), 1553-1560. http://doi.org/10.1006/anbe.1998.0914

Magee, B., \& Elwood, R. W. (2013). Shock avoidance by discrimination learning in the shore 
crab (Carcinus maenas) is consistent with a key criterion for pain. The Journal of Experimental Biology, 216(Pt 3), 353-358. http://doi.org/10.1242/jeb.072041

Mason, G. J. (2011). Invertebrate welfare: Where is the real evidence for conscious affective states? Trends in Ecology and Evolution, 26(5), 212-213. http://doi.org/10.1016/j.tree.2011.02.009

Mather, J. A., \& Anderson, R. C. (2007). Ethics and invertebrates: A cephalopod perspective. Diseases of Aquatic Organisms, 75(2), 119-129. http://doi.org/10.3354/dao075119

Mehrtens, F., Stolpmann, M., Buchholz, F., Hagen, W., \& Saborowski, R. (2005). Locomotory activity and exploration behaviour of juvenile European lobsters (Homarus gammarus) in the laboratory. Marine and Freshwater Behaviour and Physiology, 38(2), 105-116. http://doi.org/10.1080/10236240500104101

Nash, S. (2004). Desperately seeking charisma: Improving the status of invertebrates. BioScience, 54(6), 487. http://doi.org/10.1641/00063568(2004)054[0487:DSCITS]2.0.CO;2

Norwegian Animal Welfare Act 2010. https://www.regjeringen.no/en/dokumenter/animalwelfare-act/id571188/

Patterson, L., Dick, J. T., \& Elwood, R. W. (2007). Physiological stress responses in the edible crab, Cancer pagurus, to the fishery practice of de-clawing. Marine Biology, 152(2), 265272.

Proctor, H. (2012). Animal sentience: Where are we and where are we heading? Animals: An Open Access Journal from MDPI, 2(4), 628-639. http://doi.org/10.3390/ani2040628

Proctor, H. S., Carder, G., \& Cornish, A. R. (2013). Searching for animal sentience: A systematic review of the scientific literature. Animals, 3(3), 882-906. http://doi.org/10.3390/ani3030882

Roth, B., \& Grimsb $\varnothing$, E. (2013). Electrical stunning of edible crabs. (March). Nofima.

Sherwin, C. M. (2001). Can invertebrates suffer? Or, how robusts is argument-by-analogy? Animal Welfare, 1986.

Sneddon, L. U. (2004). Evolution of nociception in vertebrates: Comparative analysis of lower vertebrates. Brain Research Reviews, 46(2), 123-130. http://doi.org/10.1016/j.brainresrev.2004.07.007

Weary, D. M., Niel, L., Flower, F. C., \& Fraser, D. (2006). Identifying and preventing pain in animals. Applied Animal Behaviour Science, 100(1-2), 64-76.

http://doi.org/10.1016/j.applanim.2006.04.013 